\title{
Recorregut de recerca geològica i mineralògica per la comarca del Ripollès: des de Ribes de Freser, a Rialb, al Serrat, Vilamanya i a Queralbs
}

Josep Maria Mata-Perelló

Joaquim Sanz Balagué

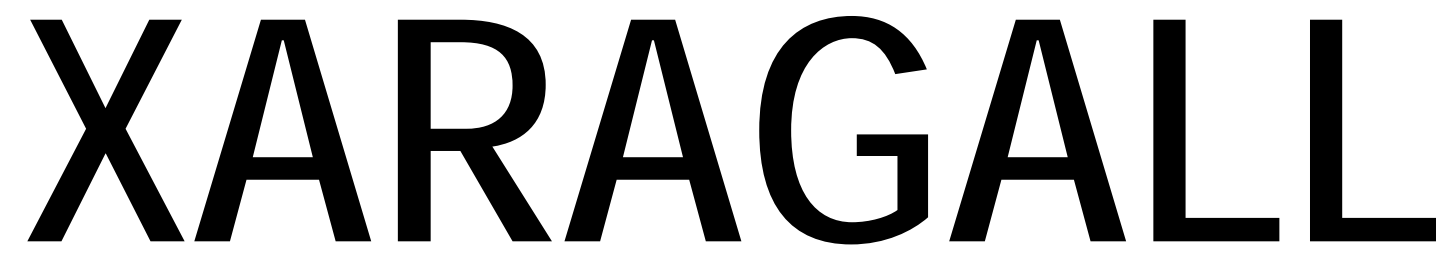

REVISTA DE CIÈNCIES DE LA CATALUNYA CENTRAL n. 7

JULIOL 2014 


\title{
RECORREGUT DE RECERCA GEOLÒGICA I MINERALÒGICA PER LA COMARCA DEL RIPOLLÈS: DES DE RIBES DE FRESER, A RIALB, AL SERRAT, VILAMANYA I A QUERALBS
}

\author{
Josep Maria Mata-Perelló \\ Museu de geologia Valentí Masachs, Escola Politècnica Superior d'Enginyeria de Manresa \\ (EPSEM), Universitat Politècnica de Catalunya · BarcelonaTech (UPC), 08272 Manresa, Spain

\section{Joaquim Sanz Balagué} \\ Departament d'Enginyeria Minera i Recursos Naturals (EMRN), Escola Politècnica Superior \\ d'Enginyeria de Manresa (EPSEM), Universitat Politècnica de Catalunya - BarcelonaTech \\ (UPC), 08272 Manresa, Spain
}

Paraules clau: Sistema Pirinenc; Pirineus Orientals; Geologia; Mineralogia

\section{Resum}

Itinerari realitzat el 2 de juny de 2013. En aquesta ocasió, el recorregut de l'itinerari discorrerà en la totalitat pel Sistema Pirinenc, i més concretament pel sector dels Pirineus Orientals. Dintre d'aquests, deambularà per dos dels seus sectors més representatius: en concret per la zona dels anomenats Apilaments Antiformes del Freser, i també per la Zona Axial, pròpiament dita.

Així, el recorregut s'iniciarà dintre dels Apilaments Antiformes del Freser, pels voltants del poble de Ribes de Freser. Finalment, els darrers trams del recorregut de l'itinerari, ja s'afectaran per la Zona Axial, en la qual clourà el recorregut, en arribar a la Mina Saragossa, del municipi de Queralt.

També cal dir, per d'altra banda, que la totalitat del recorregut, del present itinerari, es desenvoluparà per dintre de la superfície ocupada per la comarca del Ripollès, la qual pertany a la Regió de Vic. 


\section{Objectius fonamentals}

Els objectius fonamentals que es pretenen aconseguir en aquest itinerari geològic i mineralògic, són els següents:

1. Observació i estudi dels afloraments del Sistema Pirinenc, tant dels que corresponen ala Apilaments Antiformes del Freser, o com els de la Zona Axial, els quals anirem trobant a diferents indrets al llarg de tot el recorregut de l'itinerari.

2. Observació i estudi dels materials paleozoics (fonamentalment del Cambro-Ordovicià i de I'Ordovicià), que constitueixen tant els afloraments dels Apilaments Antiformes del Freser, com els de la Zona Axial. Aquests materials els tallarem pels voltants de Ribes de Freser, i entre aquesta població i la de Queralbs.

3. Estudi i descripció de les relacions i els contactes existents entre les tres unitats acabades d'esmentar al paràgrafs anteriors, i també entre els materials que les constitueixen. Així, ens referirem al denominat encavalcament de Ribes - Camprodon. el qual constitueix el límit septentrional dels Apilaments Antiformes de Ribes.

4. Estudi i descripció de diferents mineralitzacions, que anirem veient al llarg de tot el recorregut, com les següents:

4A) de les mineralitzacions ferruginoses relacionades amb l'alteració de pirites, situades prop de Vilamalla, entre els materials de I'Ordovicià.

4B) de les mineralitzacions filonianes d'antimoni i d'arsènic, situades al terme de Queralbs, entre molts altres indrets de la comarca del Ripollès. Encaixen sempre entre els materials de l'Ordovicià.

5. Observació de diferents explotacions mineres, relacionades amb les mineralitzacions acabades d'esmentar.

6. Observació del diferents elements, relacionats amb el patrimoni geològic i miner, que anirem trobant al llarg del recorregut.

\section{Antecedents}

$\mathrm{Hi}$ ha alguns antecedents, relatius a itineraris geològics i mineralògics, el quals discorren per indrets propers al present. Entre aquests, farem esment de diversos treballs nostres, com els següents: Mata-Perelló (1995, 1996a, 1996b, 1996c, 1997a, 1997b, 1998, 2007, 2011a i 2011b). També farem esment de dos treballs més, on hi ha itineraris coincidents parcialment amb el present. Es tracta de: Mata-Perelló i Font Soldevila (1995), i de Mata-Perelló i Sanz Balagué (1991).

Pel que fa a les mineralitzacions que veurem en aquest itinerari, cal dir que ja estat prèviament descrites per nosaltres en un altre treball (d'àmbit general referit al conjunt de Catalunya), al qual ens remetin. Es tracta de Mata-Perelló (1991).

Per d'altra banda, en canvi, farem esment de diversos treballs, de caràcter geològic general i regional, com són els següents: Guimerà et altri (1992), i Riba et altri (1976). Tanmateix, i pel que fa a les monografies regionals, farem esment dels treballs: IGME (1991 i 1994). 
Tots aquests treballs, figuren convenientment referenciats, per estricte ordre alfabètic, dintre de I'apartat dedicat a les referències bibliogràfiques, al qual ens remetin.

\section{Recorregut de l'itinerari}

El recorregut de l'itinerari, s'iniciarà a la població de Ribes de Freser, on s'efectuarà la primera parada del mateix. Tot seguit, I'itinerari continuarà cap a Queralbs. Abans d'arribar-hi, però caldrà agafar el camí que es dirigeix cap al poblet de Vilamanya, i posteriorment cap a l'antiga Mina Saragossa, on es farà una nova aturada, la darrera d'aquest curt itinerari.

\section{Advertiments previs}

Com en altres recorreguts de RECERCA GEOLÒGICA I MINERALÒGICA ..., semblants al present, si es disposa del temps suficient, poden efectuar-se passant per totes les parades $i$ filloles indicades al present guió. En cas contrari, recomanem prescindir de les anomenades PARADES - CONDICIONALS.

Cal dir també, que en aquest itinerari ens trobarem devent de tres trams de camins forestals en molt mal estat de conservació; per la qual cosa serà molt millor transitar a peu per ells. En aquest itinerari, hi ha alguns trams de terra, com el que es dirigeix des de Vilamalla a la Mina Saragossa.

En qualsevol cas, cal tenir sempre una cura molt especial de respecte a la natura, al llarg de tot el recorregut; de l'itinerari.

\section{Descripció de l'itinerari}

Com de costum, estructurarem el recorregut de l'itinerari en una sèrie de parades ( 0 d'estacions), que tot seguit anirem veient. En cadascuna d'aquestes aturades farem un breu comentari (geològic o mineralògic, segons s'escaigui). Per d'altra banda, en cada cas indicarem, entre parèntesi, el full topogràfic on es troba l'aturada.

Per d'altra banda, en cadascuna de les parades, indicarem entre parèntesi el número del "Mapa Topográfico", a escala 1:50.000, on es troba situada la parada considerada. Finalment, cal dir que el recorregut de l'itinerari s'inclourà dintre dels següents fulls: 217 (dit de Puigcerdà), 255 (dit de la Pobla de Lillet) i 256 (o de Ripoll).

Així doncs, la relació general ordenada de les parades que constitueixen aquest itinerari, és la següent: 


\subsection{Parada 1. CONDICIONAL. MINES DE RIALB, (Rialb, terme municipal de Queralbs, comarca del Ripollès). (Full 218).}

El recorregut de l'itinerari el començarem a la població de Ribes de Freser. Des d'aquí, ens caldrà agafar la carretera local GiV-5217, la qual es dirigeix cap a Rialb. En arribar-hi, haurem de continuar a peu, per tal d'arribar al paratge on hi ha les Coves de Can Damià. En aquest indret farem la primera aturada, a uns $3 \mathrm{Km}$ de Ribes de Freser.

En un principi, aquest recorregut, s' haurà efectuat entre afloraments dels nivells esquistosos de I'Ordovicià, entre els quals es troben freqüents intercalacions de calcàries i de dolomies. Aquests materials s'inclouen en la zona dels Apilaments Antiformes del Freser, per on ha deambulat el recorregut de l'itinerari des de la parada anterior, fins poc després de sobrepassar Ribes de Freser; doncs en trobar el camí-carretera de Batet, hem sobrepassat l'encavalcament de Ribes-Camprodon, que aquí posa en contacte els materials abans esmentats dels Apilaments Antiformes de Ribes, amb el també paleozoics de I'Ordovicià de la Zona Axial, on ara ens trobem situats. En aquest indret apareixen uns trams carbonatats del Devonià.

Precisament sobre aquests trams s' han originat les formacions kàrstiques que han donat lloc a les coves de Can Damià, les quals es troben prop d'on ara estem situats. Per d'altra banda, en aquest indret hi ha una mineralització filoniana que encaixa entre les esmentades calcaries. Entre els minerals presents, cal fer esment dels següents: ARSENOPIRITA, CALCOPIRITA, GALENA, PIRITA, així com diversos minerals d'alteració.

Finalment, cal dir que aquesta mineralització ha estat explotada en una antiga mineta, situada molt prop de la via del Cremallera.

\subsection{Parada 2. MINES DE LA CREU DE FA. MINA MARIA, (EI Serrat, terme municipal de Queralbs, comarca del Ripollès). (Full 218).}

Després de realitzar la parada anterior, cal retornar a la carretera local GiV-5217, la qual es dirigeix ara cap a Rialb, tot remuntant el riu Freser. Poc després de deixar el trencall de Vilamalla (per l'esquerra), quasi en començar la pujada cap a Queralbs, trobarem per la dreta el trencall del Serrat, cap on ens caldrà anar. Després de sobrepassar el poblet, haurem de continuar ascendint, per tal d'arribar a la Creu de Fa. En aquest indret, a uns $3 \mathrm{Km}$ del Serrat i a uns 11 de la parada anterior, n'efectuarem una altra.

En aquest recorregut, hem continuat trobant els materials paleozoics de l'Ordovicià, els quals formen part de la Zona Axial Pirenaica, on ara ens trobem situats a l'indret de la present aturada. Aquests materials es troben representats per nivells d'esquistos de la Formació Canavelles.

En aquest indret es fan clarament paleses unes escombreres, que corresponen a unes antigues explotacions mineres. En aquestes es van intentar beneficiar els minerals d'uns filonets encaixats entre els materials de l'Ordovicià. Els minerals primaris presents son els següents: ARSENOPIRITA, CALCOPIRITA, ESTIBINA, GALENA, PIRITA; així com diversos minerals d'alteració formats a partir dels anteriors. 


\subsection{Parada 3. MINES DE VILAMALLA. MINA DE "LA REPLICA", (Vilamalla, terme municipal de Queralbs, comarca del Ripollès). (Full 218).}

Després d'efectuar la parada anterior, cal retornar al Serrat, per tal de baixar fins trobar quasi el riu, arribant així de nou a la carretera GiV-5217. En trobar-la, ens haurem de dirigir cap el Sud, fins trobar per la dreta un camí-carretera, el qual es dirigeix cap a la petita població de Vilamalla. Poc abans d'arribar a aquest poblet, en una corba de la carretera, es troba una petita mineta, on efectuarem la present aturada, després d'un recorregut proper als $10 \mathrm{Km}$, des de la parada anterior.

En un principi, aquest recorregut, s' haurà efectuat entre afloraments dels nivells esquistosos de I'Ordovicià, entre els quals es troben freqüents intercalacions de calcàries i de dolomies. Aquests materials s'inclouen en la zona dels Apilaments Antiformes del Freser, per on ha deambulat el recorregut de l'itinerari des de la parada anterior, fins poc després de sobrepassar Ribes de Freser; doncs en trobar el camí-carretera de Batet, hem sobrepassat l'encavalcament de Ribes-Camprodon, que aquí posa en contacte els materials abans esmentats dels Apilaments Antiformes de Ribes, amb el també paleozoics de I'Ordovicià de la Zona Axial, on ara ens trobem situats.

En arribar a aquest indret, ens trobem davant d'una petita explotació relacionada amb els esquistos paleozoics de l'Ordovicià, sovint piritosos. Així, aquí, per oxidació de la PIRITA, ens trobem amb la presència de GOETHITA (molt limonítica i terrosa), i d'HEMATITES (també molt terròs). L'explotació consisteix en una petita galeria, oberta entre els esquits, en la qual hi ha una abundant presència de filtracions d'aigües, enriquides amb els òxids de ferro abans esmentats. (fotografia 1).

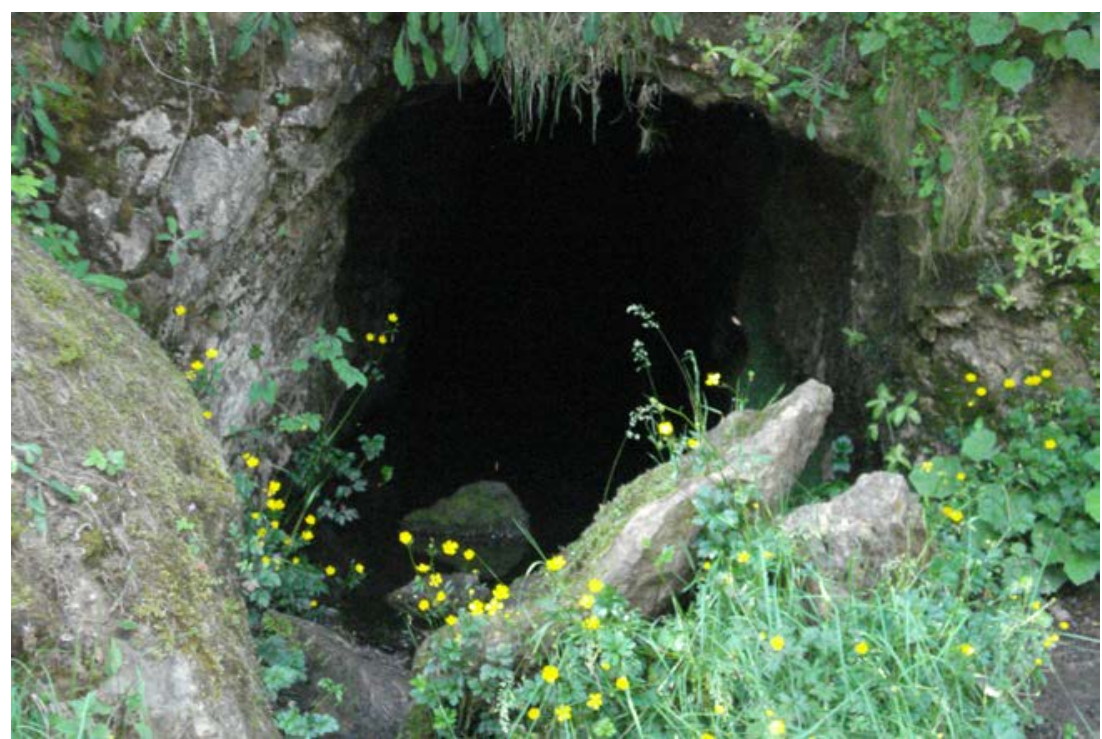

Fotografia 1. Bocamina inferior de "la Rèplica" 


\subsection{Parada 4. LABORS INFERIORS DE LA MINA SARAGOSSA, (terme municipal de Queralbs, comarca del Ripollès). (Full 218).}

Des de la parada anterior, cal continuar per la pista-carretera que es dirigeix cap al proper poble de Vilamanya. Després de sobrepassar-lo, cal continuar cap al NW, per aquest mateix camí, que ara es troba en no gaire bones condicions. Seguint per ell, ens caldrà sobrepassar el camí que se'n va cap a Planoles. Finalment, s'arribarà a la Mina Saragossa, on cal efectuar les presents aturades. Així, s' hauran recorregut des de la parada anterior, uns $4 \mathrm{Km}$. La primera d'aquestes aturades la farem a un nivell inferior de la mina, situada per sobre del camí carretera.

Tot aquest recorregut, s'haurà efectuat entre afloraments dels nivells esquistosos de I'Ordovicià, entre els quals es troben freqüents intercalacions de calcàries i de dolomies. Aquests materials s'inclouen dintre de la denominada Zona Axial, en la qual hem entrat en fer el recorregut cap a la parada anterior.

En aquest cas, després d'entrar a la bocamina situada a la bora del camí, després de recórrer una galeria de prop de 150 metres, ens trobarem amb unes interessants formacions kàrstiques. Aquestes són d'una gran bellesa. Entre aquestes formacions es troben bones cristal-litzacions d'ARAGONITA.

\subsection{Parada 5. MINA SARAGOSSA, (terme municipal de Queralbs, comarca del Ripollès). (Full 218).}

Des de la parada anterior, cal continuar a peu per la pista-carretera, remuntant un fort desnivell. Després ens caldrà pujar a peu com a la boca superior de la Mina Saragossa, on cal efectuar la present aturada. Així, s' hauran recorregut des de la parada anterior, uns $0^{\prime} 2 \mathrm{Km}$. Poc més 0 menys.

Tot aquest recorregut, s'haurà efectuat entre afloraments dels nivells esquistosos de I'Ordovicià, entre els quals es troben freqüents intercalacions de calcàries i de dolomies. Aquests materials s'inclouen dintre de la denominada Zona Axial, en la qual hem entrat en fer el recorregut cap a la parada anterior. En aquest indret, on efectuarem la present aturada, hi ha una interessant mineralització filoniana, la qual es troba encaixada entre els materials esquistosos de la Formació de Canavelles, la qual pertany a l'Ordovicià. (fotografia 2).

Entre els minerals primaris presents, cal fer esment dels següents: ARSENOPOIRITA (molt abundant), CALCOPIRITA, GALENA (indicis), PIRITA, CALCITA i QUARS (molt abundant). Entre els minerals d'alteració, cal fer esment dels següents: GOETHITA (terrosa i limonítica), HEMATITES (també terròs), ATZURITA. MALAQUITA, ESCORODITA i MELANTERITA. Tanmateix, hi ha presència d'indicis de CERUSSITA i d'ANGLESITA. Finalment, cal parlar de la presència d'ARAGONITA, i de dendrites de PIROLUSITA.

En aquest indret, va haver-hi unes interessants explotacions dels minerals d'arsènic; però amb la idea d'extreure I'OR NADIU, el qual es trobava disseminat entre l'arsenopirita. 


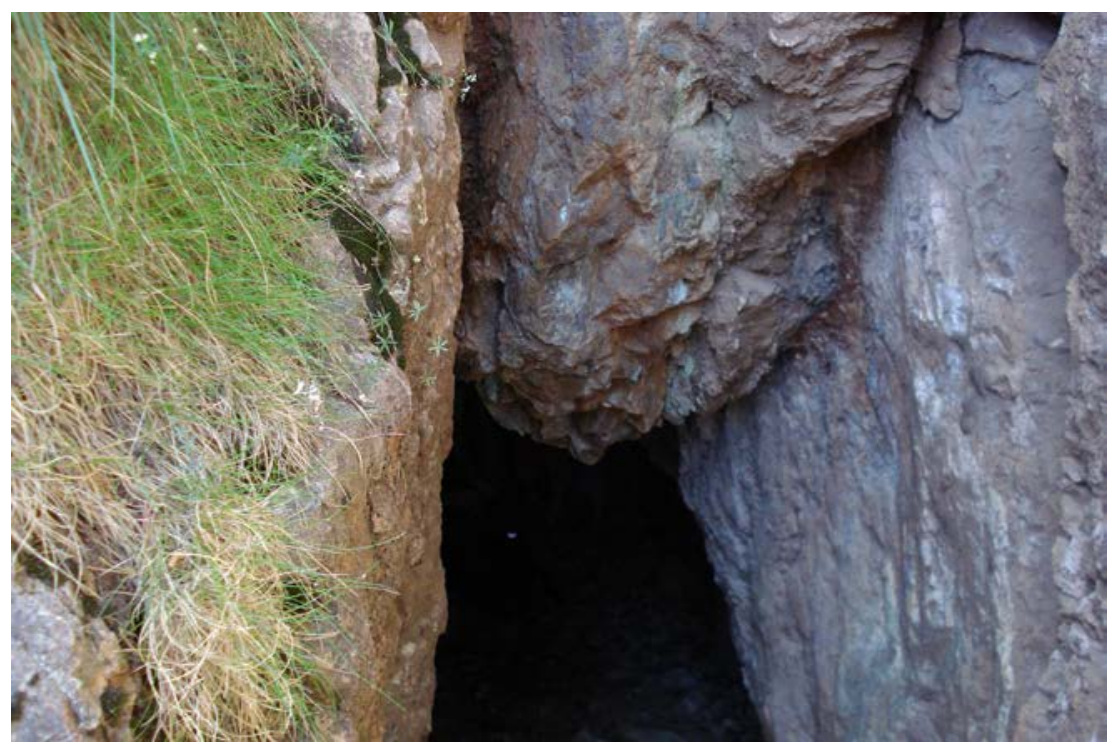

Fotografia 2. Bocamina de la Mina Saragossa

En aquest indret finalitza el recorregut de l'itinerari.

\section{Bibliografia}

GUIMERÀ, J. et altri (1992).- Geologia (II), Història Natural dels Països Catalans. Vol. 2, 547 pag. Enciclopèdia Catalana, S.A., Barcelona.

IGME (1991).- Mapa Geológico de España a escala 1:50.000 (sintesis de la cartografia existente). Full i memòria número 256 (Ripoll). Inst. Tecnol. y GeoMinero de España, Minist Indústria. Madrid.

IGME (1994).- Explicació del Mapa Geologico de España, a escala 1:50.000. Full i memòria número 255 (la Pobla de Lillet). Inst. Tecnol. y GeoMinero de España. Minist. Indústria. Madrid.

MATA-PERELLÓ, J.M. (1991).- Els Minerals de Catalunya. Arxius de la Secció de Ciències, t. XCIII, 442 pag. Institut d’Estudis Catalans. Barcelona.

MATA-PERELLÓ, J.M. (1995).- Recerca a través de la geografia física de set comarques de la Catalunya Central. Pub. Museu de Geologia de la UPC, 168 pàgines. Manresa.

MATA-PERELLÓ, J.M. (1996a).- Selecció d'itineraris geològics i mineralògics pel Berguedà, i per les seves comarques veïnes. Pub. Universitat Catalana d'Estiu de la Natura. 52 pàgines. Berga.

MATA-PERELLÓ, J.M. (1996b).- Itinerari geològico-mineralògic per les comarques del Ripollès i de la Garrotxa: des de Campdevànol a Olot i a les Preses. Inèdit, 12 pàgines, Manresa

MATA-PERELLÓ, J.M. (1996c).- Recerca geològica i mineralògica per la comarca del Ripollès: des de Campdevànol a Sant Joan de les Abadesses, Surroca de Baix, Ribes de Freser $\mathrm{i}$ Planoles. Inèdit, 10 pàg. Manresa 
MATA-PERELLÓ, J.M. (1997a).- Recerca geològica i mineralògica pel Berguedà i pel Ripollès: des de Berga a La Nou i Malanyeu, i des de la Pobla de Lillet a Campdevànol. Inèdit, 9 pàgines. Manresa

MATA-PERELLÓ, J.M. (1997b).- Recorregut de recerca geològica i mineralògica per les comarques del Berguedà i del Ripollès: des de la Pobla de Lillet a Castellar de N'Hug, a Ribes de Freser i a Queralbs. Inèdit. 10 pàgines. Manresa

MATA-PERELLÓ, J.M. (1998).- Recerca geològica i mineralògica per la comarca del Ripollès: des de Campdevànol a Ribes de Freser, Queralbs i a Planés de Rigart. Inèdit. 11 pag. Manresa

MATA-PERELLÓ, J.M. (2007).- Recerca geològica y mineralògica per la comarca del Ripollès: des de Campdevànol a Ribes de Freser, Queralbs, Planoles i Toses. Inèdit. 12 pag. Manresa

MATA-PERELLÓ, J.M. (2011a).- Recerca geològica i mineralògica per la comarca del Ripollès: des de Campdevànol a Ribes de Freser, Queralbs, Planoles i a Toses. Inèdit. 11 pàgines. Manresa

MATA-PERELLÓ, J.M. (2011b).- Recerca geològica i mineralògica per la comarca del Ripollès: des de Ribes de Fresser, al Serrat, a Vilamalla i a Queralbs. Inèdit. 8 pàgines. Manresa

MATA-PERELLÓ, J.M. i FONT SOLDEVILA, J. (1995).- Itinerari geològic-mineralògic pel Berguedà. Apunts EUPM, 78 pag. Barcelona.

MATA-PERELLÓ, J.M. i SANZ BALAGUÉ, J. (1991).- Guia de determinació dels minerals. Països Catalans i Altres. Edic. Parcir. Manresa.

RIBA ARDERIU, O. Et altri. (1976).- Geografia física dels Països Catalans. Edit Ketres. Barcelona 